\title{
Papers
}

\section{Randomised controlled trial of physiotherapy compared with advice for low back pain}

\author{
Helen Frost, Sarah E Lamb, Helen A Doll, Patricia Taffe Carver, Sarah Stewart-Brown
}

\begin{abstract}
Objective To measure the effectiveness of routine physiotherapy compared with an assessment session and advice from a physiotherapist for patients with low back pain. Design Pragmatic, multicentre, randomised controlled trial. Setting Seven British NHS physiotherapy departments. Participants 286 patients with low back pain of more than six weeks' duration.

Intervention Routine physiotherapy or advice on remaining active from a physiotherapist. Both groups received an advice book.

Main outcome measures Primary outcome was scores on the Oswestry disability index at 12 months. Secondary outcomes were scores on the Oswestry disability index (two and six months), scores on the Roland and Morris disability questionnaire and SF-36 (2, 6 and 12 months), and patient perceived benefit from treatment (2, 6, and 12 months). Results 200 of 286 patients (70\%) provided follow up information at 12 months. Patients in the therapy group reported enhanced perceptions of benefit, but there was no evidence of a long term effect of physiotherapy in either disease specific or generic outcome measures (mean difference in change in Oswestry disability index scores at 12 months $-1.0 \%$, $95 \%$ confidence interval $-3.7 \%$ to $1.6 \%$ ). The most common treatments were low velocity spinal joint mobilisation techniques (72\%, 104 of 144 patients) and lumbar spine mobility and abdominal strengthening exercises (94\%, 136 patients).

Conclusions Routine physiotherapy seemed to be no more effective than one session of assessment and advice from a physiotherapist.
\end{abstract}

\section{Introduction}

Disability associated with low back pain is a major public health problem in Western societies. ${ }^{1-4}$ Back pain is the most common cause of physical disability in the working age population of the United Kingdom. ${ }^{2}$ In 1998, the direct healthcare costs for back pain in the United Kingdom were estimated at $£ 1632 \mathrm{~m}$ (\$2932m; €2423m), with physiotherapy accounting for $£ 251 \mathrm{~m} .{ }^{3}$ Physiotherapy is a tailored intervention that is usually focused on physical factors, including a combination of joint mobilisation, advice, and individual exercise programmes. ${ }^{5}$

Physiotherapists in the British NHS treat around 1.3 million people for low back pain each year, but there is only weak evidence for the effectiveness of routine physiotherapy and no evidence for the effectiveness of electrotherapy, laser treatment, ultrasound therapy, or traction. ${ }^{2}{ }^{6}$
International guidelines vary but agree on advising patients with low back pain to remain physically active and prescribing appropriate analgesics. They recommend exercise therapy for patients with chronic low back pain ( $>12$ weeks' duration) and some suggest spinal manipulation for acute or subacute low back pain. $^{7-9}$ We investigated the effectiveness of physiotherapy, as commonly practised in the British NHS, over a year for patients with low back pain compared with one session of assessment and advice from a physiotherapist.

\section{Methods}

The protocol for the treatment arm allowed physiotherapists to select from a range of manual therapy techniques and exercise treatments. Patients were recruited from the health service settings where they received the treatment.

\section{Participants and eligibility}

We carried out a multicentre, investigator blinded, randomised controlled trial, with written consent from all the patients. Participants were identified from physiotherapy referrals made by general practitioners and consultants. They were invited to participate from seven physiotherapy departments based in NHS outpatient departments in Oxfordshire and Reading, Berkshire.

Research therapists in each of the centres contacted the patients to check eligibility. The baseline assessment included red flag screening questions to exclude the possibility of serious dis-

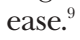

Our inclusion criteria were age 18 years and over with low back pain for at least six weeks with or without leg pain or neurological signs. We excluded patients with serious conditions, including systemic rheumatological disease, gynaecological problems, ankylosing spondylitis, tumours, infection, past spinal operations, and treatment for physical problems in the past month. We also excluded patients referred for intensive functional restoration programmes.

\section{Outcome measures}

Our primary outcome measure was scores on the Oswestry disability index at 12 months: $0 \%$ (no disability) to 100\% (totally disabled or bed ridden). ${ }^{10}$

Our secondary outcome measures were scores on the Oswestry disability index at two and six months and scores on the Roland and Morris disability questionnaire at 2, 6, and 12 months. ${ }^{10} 11$ This questionnaire contains 24 items relating to a

Results for patients with valid data at each assessment are on bmj.com 
range of functions commonly affected by low back pain: 0 (best health) to 24 (worst health). General health was measured with the SF-36 at 2, 6, and 12 months (higher scores indicate better health). ${ }^{12}$ Patient perceived benefit of treatment was measured on a scale from 0 (no benefit) to 10 (maximum benefit) and on a dichotomous scale (perceived benefit or no perceived benefit).

Follow up data were collected by postal questionnaire by a research assistant blind to treatment allocation. Non-responders received reminders by post. If this was unsuccessful the patients were telephoned. Data were double entered.

\section{Intervention}

Patients were randomised to receive advice to remain active (advice only group) or advice and a standard course of physiotherapy (therapy group). Both groups were given an advice book, and information from this was discussed with the physiotherapist. ${ }^{13}$ Advice was directed towards promoting self-management and modifying beliefs and behaviour. Physiotherapy was initiated within the week after randomisation.

\section{Advice only group}

Patients in the advice only group received one session with a physiotherapist, who carried out a physical examination and gave general advice to remain active, as specified in the advice book. The session lasted for up to an hour.

\section{Therapy group}

Patients in the therapy group underwent a physical examination by physiotherapists, lasting up to one hour. In line with usual practice, the physiotherapists chose a treatment strategy based on their findings but agreed to treat according to a standardised protocol reflecting routine NHS practice. ${ }^{5}$ This included any combination of joint mobilisation and manipulation; soft tissue techniques, including stretching; spinal mobility and strengthening exercises; heat or cold treatment; and advice. The protocol specified up to five additional treatment sessions of around 30 minutes. Physiotherapists recorded the type and number of sessions.

\section{Randomisation and blinding}

The allocation sequence was determined before the study by a research assistant using a computer generated random number sequence. ${ }^{14}$ Groups were coded and the allocation transferred to opaque, sealed, sequentially numbered envelopes. No stratification was used.

The allocation was concealed from the research therapist who carried out the baseline assessment, the data manager who recorded the data, and the statistician carrying out the analysis. The code for the grouping was known only to the physiotherapists treating the patients. The allocation was concealed from each patient until the first appointment.

Although the investigators were blinded to treatment allocation, it was not possible to mask the intervention from the patients or the physiotherapists beyond the baseline assessment for practical and ethical reasons. The baseline assessment was carried out by the research therapist before randomisation.

\section{Statistical analysis}

We estimated the required sample size a priori, assuming a power of $90 \%$ and an $\alpha$ of $0.05 .{ }^{15}$ Our sample size was calculated to detect a minimally clinically important difference between groups of $4 \%$ (standard deviation $8.0 \%$ ) points in scores on the Oswestry disability index, giving an estimated sample size of 112 patients in each group (224 in total). We aimed to recruit at least 270 patients to allow for losses during follow up.
All analyses were performed on an intention to treat basis. To address potential biases due to incomplete follow up, we analysed patients with complete data at all time points and those with data at any time point, using the last known value carried forward to replace missing values. Outcome data for change in scores from baseline were compared between the groups. Bias due to non-response was assessed at each follow up.

The distributions of data were checked to ensure that parametric assumptions were met, and non-parametric analyses were used when appropriate. We used independent $t$ tests or Mann-Whitney $\mathrm{U}$ tests for continuous data and $\chi^{2}$ tests for categorical data for unadjusted comparisons. Analysis of covariance was used to assess the effects of treatment at each time point, with baseline scores as the covariate, and adjusting for differences in age, sex, smoking status, and time since first episode of back pain. We examined the effects of treatment over all time points using repeated measures analysis of covariance. Relative risks were used to assess the differences between the groups for perceived benefit of physiotherapy, with logistic regression used for adjusted comparisons. Data are presented as mean (standard deviation) scores or numbers (percentages), with 95\% confidence intervals. Data were analysed with SPSS version 10.0.

\section{Results}

Between October 1997 and January 2001 we randomised 286 (56.3\%) of 508 patients who had been assessed for eligibility: 144 were allocated to therapy and 142 to advice only (fig 1). Table 1 lists the patients' characteristics. Although the advice only group had a slightly greater proportion of men and smokers, the groups were well balanced otherwise.

\section{Treatment}

The patients were treated by 76 physiotherapists, reflecting the high turnover of staff in British NHS hospitals. About half (53\%) of all treatments were carried out by 29 senior 1 therapists, $32 \%$ by 25 senior 2 therapists, and the remainder by junior grades. Treatment in the therapy group included joint mobilisation using low velocity thrusts (104 of 144 patients; 72\%); soft tissue techniques $(20 ; 14 \%)$; specific exercises (for example, McKenzie regimens) ${ }_{1}^{16}$ abdominal stability or strengthening exercises, and general mobility exercises for the lumbar spine $(136 ; 94 \%)$; and heat $(9 ; 6 \%)$ or cold treatment $(4 ; 3 \%)$. The use of high velocity thrusts was rare $(4 ; 3 \%)$.

Overall, $82 \%$ of patients in both groups complied with treatment. Patients in the therapy group received a median number of five (range 1-12) sessions, with 118 (82\%) having six or fewer. Twenty six (18\%) patients received more than six sessions as a result of decisions made by the physiotherapist. The median number of sessions in the advice only group was one (range 1-22). The number of single sessions was 116 , with 26 patients receiving extra sessions either because they were unhappy with advice only (eight patients), because the physiotherapist deemed it unethical to withhold further treatment (for example, sudden increase in severe pain; four patients), or because the patient had been rereferred by his or her general practitioner for more treatment (two patients). No reason was given for extra sessions in the other patients.

\section{Bias due to non-response}

Overall, $30 \%$ of patients failed to provide data for the main outcome at 12 months. Only minor differences were found in the characteristics of people completing or not completing the Oswestry disability index at all follow up points: responders were older (mean age 43 (SD 15) v $37(13) ; \mathrm{P}<0.001)$, less likely to 


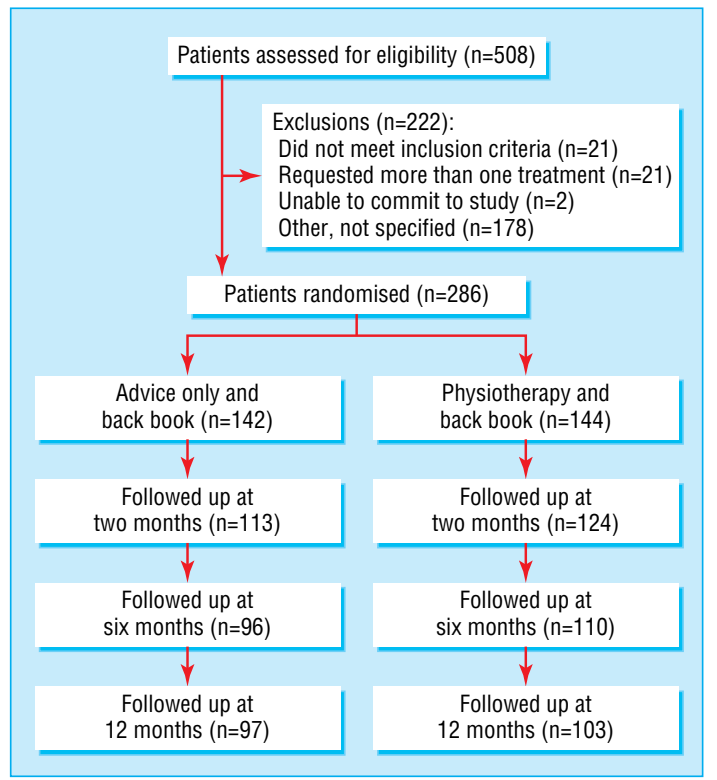

Flow of patients through trial

smoke (39 (22\%) v $50(47 \%) ; \mathrm{P}<0.001)$, and more likely to have a first episode of back pain or a history of chronic back pain (39 $(23 \%)$ v $14(15 \%)$ and $43(25 \%)$ v $14(15 \%)$, respectively; $\mathrm{P}=0.009)$.

\section{Outcome measures and patient perceived treatment benefit}

We found no differences between the groups in change in scores on the Oswestry disability index at 12 months (mean difference $-1.04,95 \%$ confidence interval -3.7 to 1.59 ). Tables 2 and 3 show the results derived from the last value carried forward analysis.

At 12 months the mean difference in domain scores on the SF-36 were: physical function $(2.76,95 \%$ confidence interval -1.91 to 7.42$)$, role physical $(0.68,-9.54$ to 10.9$)$, bodily pain (6.16, 0.45 to 11.9$)$, general health $(-0.31,-4.15$ to 3.53$)$, vitality $(1.45,-2.41$ to 5.32$)$, social functioning $(3.26,-2.39$ to 8.91$)$, role emotional $(8.65,-0.87$ to 18.2$)$, and mental health (2.19, -1.59 to 5.97$)$. Patients in the therapy group reported greater improvements for mental health and physical functioning at two months than the advice only group. On the basis of non-significant repeated measures analysis of covariance, however, these results are likely to be attributable to multiple testing. Overall, the data are consistent with no benefit from additional physiotherapy. Results from both methods of analysis were similar.

Patients in the therapy group were more likely to report benefits from treatment at both two and six months and also more benefit on the $0-10$ rating scale at all time points than patients in the advice only group (table 4 ).

\section{Discussion}

Routine physiotherapy for mild to moderate low back pain generally practised in the United Kingdom is no more effective than a session with a physiotherapist that includes advice. The patients' perception of treatment benefit was, however, in conflict with the validated outcome measures, and the clinical importance of this finding needs further investigation.

Our trial does not provide information on the effectiveness of advice compared with no intervention, but other trials suggest that advice supported by a booklet is a useful intervention when
Table 1 Personal characteristics at baseline of 286 patients allocated to receive physiotherapy and advice for low back pain or advice only. Values are numbers (percentages) unless stated otherwise

\begin{tabular}{|c|c|c|}
\hline Characteristics & Therapy group $(n=144)$ & Advice only group ( $n=142)$ \\
\hline Mean (SD) age (years) & $41.7(14.9)$ & $40.0(13)$ \\
\hline Women & $83(58)$ & $67(47)$ \\
\hline Men & $61(42)$ & $75(53)$ \\
\hline In employment & $100(70)$ & $104(74)$ \\
\hline Smoker & $40(28)$ & $49(35)$ \\
\hline \multicolumn{3}{|l|}{ Source of referral: } \\
\hline General practitioner & $130(91)$ & $126(89)$ \\
\hline Consultant & $9(6)$ & $9(6)$ \\
\hline Triage & $4(3)$ & $6(4)$ \\
\hline Sports clinic & 0 & $1(1)$ \\
\hline \multicolumn{3}{|l|}{ Duration of back pain episode: } \\
\hline $6-12$ weeks & $32(23.0)$ & $35(25.5)$ \\
\hline 3-6 months & $35(25.2)$ & $31(22.6)$ \\
\hline 6-12 months & $23(16.5)$ & $22(16.1)$ \\
\hline$\geq 12$ months & $49(35.3)$ & $49(35.8)$ \\
\hline \multicolumn{3}{|l|}{ First episode of back pain: } \\
\hline$<1$ year & $27(20.0)$ & $26(19.8)$ \\
\hline $1-6$ years & $51(37.8)$ & $54(41.2)$ \\
\hline $6-11$ years & $26(19.3)$ & $25(19.1)$ \\
\hline$\geq 11$ years & $31(23.0)$ & $26(19.8)$ \\
\hline $\begin{array}{l}\text { Previous treatment for low } \\
\text { back pain }\end{array}$ & $84(58.3)$ & $86(60.6)$ \\
\hline $\begin{array}{l}\text { Mean (SD) Oswestry disability } \\
\text { index score }\end{array}$ & $21.12(11.08)$ & $21.60(11.00)$ \\
\hline $\begin{array}{l}\text { Mean (SD) Roland and Morris } \\
\text { disability questionnaire } \\
\text { score }\end{array}$ & 6.12 (4.39) & $5.91(4.27)$ \\
\hline \multicolumn{3}{|l|}{ Mean (SD) SF-36 score: } \\
\hline Physical functioning & $69.3(19.3)$ & $68.7(22.8)$ \\
\hline Role physical & $43.2(40.6)$ & $44.3(39.8)$ \\
\hline Bodily pain & $42.7(18.1)$ & $44.6(20.5)$ \\
\hline General health & $66.6(19.2)$ & $68.5(18.9)$ \\
\hline Vitality & $52.7(19.2)$ & $53.5(17.6)$ \\
\hline Social functioning & $73.6(25.9)$ & 77.5 (22.4) \\
\hline Role emotional & $72.0(38.7)$ & $73.5(38.4)$ \\
\hline Mental health & $70.0(16.5)$ & $72.8(16.0)$ \\
\hline $\begin{array}{l}\text { Physical component } \\
\text { summary }\end{array}$ & 49.6 ( 9.6) & $50.4(10.4)$ \\
\hline $\begin{array}{l}\text { Mental component } \\
\text { summary }\end{array}$ & $49.4(9.7)$ & $50.6(10.3)$ \\
\hline
\end{tabular}


Table 2 Mean (SD) change in disease specific scores at 2, 6, and 12 months from baseline for patients receiving physiotherapy or advice only for low back pain, with missing data replaced using last value carried forward

$$
\text { Therapy group }(n=144) \quad \text { Advice only group }(n=142)
$$

P value*

$\begin{array}{cc}\text { Repeated } \\ \text { Analysis of } & \begin{array}{c}\text { measures } \\ \text { analysis of } \\ \text { covariance }\end{array} \\ \text { covariancet }\end{array}$

Instrument

Mean (SD) change Effect size

Mean (SD) change

Effect size

Mean difference $(95 \% \mathrm{CI})$

\begin{tabular}{|c|c|c|c|c|c|c|c|}
\hline 2 months & $-2.65(9.34)$ & 0.24 & $-1.33(9.29)$ & 0.12 & $-1.32(-3.50$ to -0.86$)$ & $0.20(0.17)$ & 0.24 \\
\hline 6 months & $-2.89(11.59)$ & 0.26 & $-1.83(10.61)$ & 0.17 & $-1.06(-3.66$ to 1.54$)$ & $0.36(0.31)$ & \\
\hline 12 months & $-3.27(10.99)$ & 0.29 & $-2.23(11.47)$ & 0.20 & $-1.04(-3.70$ to 1.59$)$ & $0.33(0.28)$ & \\
\hline \multicolumn{8}{|c|}{$\begin{array}{l}\text { Roland and Morris disability } \\
\text { questionnaire: }\end{array}$} \\
\hline 2 months & $-1.13(3.98)$ & 0.26 & $-0.56(3.38)$ & 0.13 & $-0.56(-1.42$ to 0.30$)$ & $0.20(0.32)$ & 0.46 \\
\hline 6 months & $-1.19(4.74)$ & 0.27 & $-0.79(4.20)$ & 0.18 & $-0.40(-1.44$ to 0.64$)$ & $0.45(0.61)$ & \\
\hline 12 months & $-1.36(4.66)$ & 0.31 & $-0.99(4.23)$ & 0.23 & -0.38 ( -1.41 to 0.66$)$ & $0.48(0.62)$ & \\
\hline
\end{tabular}

${ }^{*} t$ test.

†Adjusted for score at baseline, age, sex, smoking status, and time since first episode of back pain

compared with usual care given by a general practitioner as long as the information is reinforced by all involved in the patients care. ${ }^{17}{ }^{18}$ Although physiotherapists usually give advice, the book we chose is not used as standard practice in most physiotherapy departments. Spinal manipulation, which physiotherapists can provide after specialist postgraduate training, was negligible in our trial, although some international guidelines suggest that it may be helpful for acute or subacute low back pain.
There were only a few minor differences in baseline characteristics between patients who did or did not provide complete data, but the internal validity of our study is limited because $30 \%$ of patients failed to provide data for the main outcomes at 12 months.

We addressed potential bias by replacing missing data with the last value carried forward. Estimates of the effect of treatment were similar with both methods of analysis. Our trial highlights

Table 3 Mean (SD) change in SF-36 domain scores at 2, 6 and 12 months from baseline for patients receiving physiotherapy or advice only for low back pain, with missing data replaced using last value carried forward

\begin{tabular}{|c|c|c|c|c|c|c|c|}
\hline \multirow[b]{2}{*}{ Domain } & \multicolumn{2}{|c|}{ Therapy group $(n=144)$} & \multicolumn{2}{|c|}{ Advice only group ( $\mathrm{n}=142$ ) } & \multirow[b]{2}{*}{ Mean difference $(95 \% \mathrm{Cl})$} & \multicolumn{2}{|c|}{ P value* } \\
\hline & Mean (SD) change & Effect size & $\begin{array}{l}\text { Mean (SD) } \\
\text { change }\end{array}$ & Effect size & & $\begin{array}{l}\text { Analysis of } \\
\text { covariance } \dagger\end{array}$ & $\begin{array}{l}\text { Repeated measures } \\
\text { analysis of covariance }\end{array}$ \\
\hline \multicolumn{8}{|c|}{ Physical function: } \\
\hline 2 months & $5.24(19.99)$ & 0.27 & $1.70(16.10)$ & 0.07 & $3.55(-0.52$ to 7.61$)$ & $0.09(0.037)$ & \multirow[t]{3}{*}{0.06} \\
\hline 6 months & $5.43(18.80)$ & 0.28 & $2.77(17.07)$ & 0.12 & 2.66 (-1.53 to 6.86$)$ & $0.21(0.098)$ & \\
\hline 12 months & $5.98(20.98)$ & 0.31 & $3.22(18.87)$ & 0.14 & 2.76 (-1.91 to 7.42$)$ & $0.25(0.095)$ & \\
\hline \multicolumn{8}{|l|}{ Role physical: } \\
\hline 2 months & 14.99 (39.35) & 0.37 & $10.80(35.77)$ & 0.27 & $4.19(-4.57$ to 12.9$)$ & $0.35(0.60)$ & \multirow[t]{3}{*}{0.97} \\
\hline 6 months & $15.91(46.41)$ & 0.39 & $14.26(38.87)$ & 0.36 & $1.65(-8.31$ to 11.6$)$ & $0.74(0.97)$ & \\
\hline 12 months & $13.89(45.11)$ & 0.34 & $13.20(42.70)$ & 0.33 & 0.68 (-9.54 to 10.9) & $0.90(0.83)$ & \\
\hline \multicolumn{8}{|l|}{ Bodily pain: } \\
\hline 2 months & $9.70(20.53)$ & 0.54 & $7.47(19.33)$ & 0.37 & 2.22 (-2.41 to 6.87$)$ & $0.35(0.39)$ & \multirow[t]{3}{*}{0.16} \\
\hline 6 months & $13.35(22.88)$ & 0.74 & $10.49(21.78)$ & 0.51 & 2.86 (-2.34 to 8.06$)$ & $0.28(0.37)$ & \\
\hline 12 months & $16.79(24.34)$ & 0.93 & $10.63(24.70)$ & 0.52 & $6.16(0.45$ to 11.9$)$ & $0.035(0.057)$ & \\
\hline \multicolumn{8}{|l|}{ General health: } \\
\hline 2 months & $-0.15(14.23)$ & 0.01 & $-0.24(12.76)$ & 0.01 & $0.09(-3.05$ to 3.24$)$ & $0.95(0.73)$ & \multirow[t]{3}{*}{0.39} \\
\hline 6 months & $-1.36(16.01)$ & 0.07 & $0.06(13.97)$ & 0.00 & $-1.42(-4.92$ to 2.08$)$ & $0.43(0.16)$ & \\
\hline 12 months & $-1.66(15.92)$ & 0.09 & $-1.35(17.05)$ & 0.07 & $-0.31(-4.15$ to 3.53$)$ & $0.87(0.62)$ & \\
\hline \multicolumn{8}{|l|}{ Vitality: } \\
\hline 2 months & $2.01(16.26)$ & 0.11 & $0.62(13.74)$ & 0.04 & $1.39(-2.11$ to 4.90$)$ & $0.44(0.30)$ & \multirow[t]{3}{*}{0.57} \\
\hline 6 months & $1.77(17.87)$ & 0.09 & $1.17(13.30)$ & 0.07 & $0.60(-3.07$ to 4.26$)$ & $0.75(0.72)$ & \\
\hline 12 months & $2.55(17.85)$ & 0.13 & 1.09 (15.26) & 0.06 & 1.45 (-2.41 to 5.32$)$ & $0.46(0.43)$ & \\
\hline \multicolumn{8}{|c|}{ Social functioning: } \\
\hline 2 months & $6.25(22.08)$ & 0.24 & $1.67(19.54)$ & 0.07 & 4.58 (-0.17 to 9.43$)$ & $0.06(0.24)$ & \multirow[t]{3}{*}{0.28} \\
\hline 6 months & $8.51(25.16)$ & 0.33 & $2.64(20.02)$ & 0.12 & 5.87 ( 0.58 to 11.2$)$ & $0.03(0.12)$ & \\
\hline 12 months & $5.90(25.13)$ & 0.23 & $2.64(23.39)$ & 0.12 & 3.26 (-2.39 to 8.91$)$ & $0.26(0.67)$ & \\
\hline \multicolumn{8}{|c|}{ Role emotional: } \\
\hline 2 months & $6.53(39.61)$ & 0.17 & $1.41(36.57)$ & 0.04 & 5.12 (-3.77 to 14.0$)$ & $0.26(0.36)$ & \multirow[t]{3}{*}{0.21} \\
\hline 6 months & $3.03(36.02)$ & 0.08 & $-0.94(41.63)$ & 0.02 & $3.97(-5.11$ to 13.0$)$ & $0.39(0.46)$ & \\
\hline 12 months & $5.36(40.66)$ & 0.14 & $-3.29(40.93)$ & 0.09 & 8.65 (-0.87 to 18.2$)$ & $0.08(0.065)$ & \\
\hline \multicolumn{8}{|l|}{ Mental health: } \\
\hline 2 months & $2.46(13.17)$ & 0.15 & $-2.45(13.67)$ & 0.15 & 4.91 (1.79 to 8.06$)$ & $0.002(0.006)$ & \multirow[t]{3}{*}{0.10} \\
\hline 6 months & $1.15(14.46)$ & 0.07 & $-1.41(14.88)$ & 0.09 & 2.55 (-0.86 to 5.97$)$ & $0.14(0.22)$ & \\
\hline 12 months & 0.64 (15.89) & 0.04 & $-1.55(16.56)$ & 0.10 & $2.19(-1.59$ to 5.97$)$ & $0.26(0.25)$ & \\
\hline
\end{tabular}

*t test.

†Adjusted for baseline score, age, sex, smoking status, and time since first episode of back pain. 


\begin{tabular}{|c|c|c|c|c|c|c|}
\hline Patient perceived benefit & $\begin{array}{l}\text { Therapy group } \\
\quad(\mathrm{n}=144)\end{array}$ & $\begin{array}{l}\text { Advice only group } \\
(\mathrm{n}=142)\end{array}$ & $\begin{array}{l}\text { Relative risk of benefit }(95 \% \\
\text { CI) }\end{array}$ & Mean difference $(95 \% \mathrm{Cl})$ & \multicolumn{2}{|c|}{$P$ value } \\
\hline \multicolumn{7}{|l|}{ Two months: } \\
\hline Benefit & $93(76.9)$ & $64(59.8)$ & 1.29 (1.07 to 1.54$)$ & & $0.009^{*}$ & $0.002 \dagger$ \\
\hline No benefit & $28(23.1)$ & $43(40.2)$ & - & & & \\
\hline \multicolumn{7}{|l|}{ Six months: } \\
\hline Benefit & $82(64.6)$ & $56(50.5)$ & 1.28 (1.02 to 1.60$)$ & & $0.039^{*}$ & $0.007 \dagger$ \\
\hline No benefit & $45(35.4)$ & $55(49.5)$ & - & & & \\
\hline $\begin{array}{l}\text { Patient perceived benefit }(0-10 \\
\text { scale): }\end{array}$ & $\mathrm{n}=119$ & $\mathrm{n}=103$ & & & & \\
\hline \multirow[t]{2}{*}{2 months } & $5.42(2.84)$ & $3.66(2.78)$ & & 1.76 (1.01 to 2.51$)$ & $0.001 \ddagger$ & $<0.001 \S$ \\
\hline & $\mathrm{n}=125$ & $\mathrm{n}=109$ & & & & \\
\hline \multirow[t]{2}{*}{6 months } & $4.74(3.24)$ & $3.61(2.98)$ & & 0.93 (0.03 to 1.83 ) & $0.006 \ddagger$ & $0.002 \S$ \\
\hline & $\mathrm{n}=126$ & $\mathrm{n}=112$ & & & & \\
\hline 12 months & $5.02(3.12)$ & $4.13(2.95)$ & 0.87 (0.02 to 1.72$)$ & & $0.025 \ddagger$ & $0.011 \S$ \\
\hline
\end{tabular}

the difficulty in interpreting results with relatively high rates of non-response. Other trials of low back pain report similar findings, and researchers should be aware of this when designing trials for the future. ${ }^{17} 19$

Compliance with treatment is rarely assessed or adequately reported in randomised controlled trials, and although it is common for patients to seek additional treatment, little is reported or known about the clinicians' compliance with trial protocols. ${ }^{20} \mathrm{We}$ encouraged only physiotherapists who reported clinical equipoise to be involved in the trial, but the reasons for non-compliance are complex and we could not control for clinical decisions made on the basis of patients' fluctuating symptoms and physiotherapists' beliefs about the effectiveness of treatment.

\section{Comparison with related research}

According to disease specific outcomes, our participants had mild to moderate low back pain. The SF-36 scores in our trial population were similar to those of patients with back pain in the general population consulting physiotherapists and worse than those of non-consulting patients with back pain. ${ }^{21}$

Similar baseline disease specific disability scores have been reported in only one other British study of patients with subacute low back pain.2 ${ }^{22}$ This trial found larger health gains in patients who attended a fitness programme to increase confidence in the use of their spine and to overcome fear of exercise. This suggests that exercise programmes with good compliance that are graded to ensure improvements in cardiovascular or muscular strength are more beneficial than routine physiotherapy carried out in this trial and generally practised in the United Kingdom.

Our results are generalisable since patients were recruited from routine referrals, and the interventions included commonly delivered treatments. Despite patient perceived benefits captured by a global indicator, the results suggest that the traditional model of physiotherapy should be challenged.

We thank the physiotherapists: Farida Barma, David Beard, Helen Dawes, Kirstie Haywood, Valerie McKee, Mary Pinkney, and Liz Walker; the senior physiotherapists and managers, particularly Emy Pilgrim, involved in the initial planning of the trial; the 76 physiotherapists for their cooperation and treatment of patients; and the participants. This trial was begun and implemented while HF and SEL were working in the Physiotherapy Research Unit, Nuffield Orthopaedic Centre Oxford, and we thank the staff for their help. We thank Oliver Rivero-Arias for his comments on the early drafts.

Contributors: HF and SS-B developed the protocol, secured initial funding, and implemented the study. HF, SS-B and SEL obtained long term funding and directed the study. HD carried out the main statistical analysis. HF wrote the original draft with SS-B, SEL, and HD. PT-C helped with the final draft, entered the data, organised the trial, and carried out some categorical analysis of data. HF, SEL, and SS-B are guarantors.

Funding: Arthritis Research Campaign.

Competing interests: None declared.

Ethical approval: This study was approved by the Oxford Nursing and Allied Professions research ethics committee and the West Berkshire local ethics committee.

1 Klaber Moffett J, Richardson G, Sheldon TA, Maynard A. Back pain. Its management and cost to society. University of York: Centre for Health Economics, NHS Centre for Reviews and dissemination, 1995. (Discussion paper No 129.)

2 Clinical Standards Advisory Group. Epidemiology review: the epidemiology and cost of back pain. London: HMSO, 1994.

Maniadakis N, Gray A. The economic burden of back pain in the UK. Pain 2000;84:95103.

4 Knight M, Stewart-Brown S, Fletcher L. Estimating health needs: the impact of a checklist of conditions and quality of life measurement on health information derived from community surveys.J Public Health Med 2001;23:179-86.

5 Foster N, Thompson K, Baxter G, Allen JM. Management of non-specific low back pain by therapists in Britain and Ireland. Spine 1999;24:1332-42.

6 Bekkering GE, Hendriks HJM, Koes BW, Oostendorp RAB, Ostelo RWJG, Thomassen JMC, et al. Dutch physiotherapy guidelines for low back pain. Physiotherapy 2003;89(2):82-96.

7 Koes BW, van Tulder MW, Ostelo R, Burton KA, Waddell G. Clinical guidelines for the management of low back pain in primary care. An international comparison. Spine 2001:26:2504-14.

8 Van Tulder M, Malmivaara A, Esmail R, Koes B. Exercise therapy for low back pan. A systematic review within the framework of the Cochrane collaboration back review group. Spine 2000;25:2784-96.

9 Clinical Standards Advisory Group. Back pain. London: HMSO, 1994

10 Fairbank J, Pynsent P. The Oswestry disability index. Spine 2000;25:2940-53.

\section{What is already known on this topic}

International guidelines for patients with low back pain vary

All agree that patients should be advised to stay active; some suggest spinal manipulation for acute and subacute low back pain and most advise exercise therapy for chronic low back pain

It is unclear which type or intensity of exercise is most effective and strong evidence is lacking for the effectiveness of other treatments

\section{What this study adds}

Routine physiotherapy for patients with mild to moderate low back pain is no more effective in the long term than advice given by a physiotherapist 
11 Roland M, Morris R. A study of the natural history of back pain. Part 1: development of a reliable and sensitive measure of disability in low back pain. Spine 1993;8:141-4.

12 Brazier JE, Harper R, Jones NMB, Ocathain A, Thomas KJ, Usherwood T, et al. Validating the SF-36 health survey questionnaire; new outcome measure for primary care. BMJ 1992;305:160-4

13 The back book. London: Stationery Office, 1997.

14 Pocock SJ. Clinical trials. A practical approach. Chichester: Wiley, 1983.

15 Kirkwood BR. Essentials of medical statistics. Oxford: Blackwell, 1990.

16 McKenzie RA. The lumbar spine: mechanical diagnosis and therapy. Waikanae, New Zealand: Spine, 1981.

17 Little P, Roberts L, Blowers H, Garwood J, Cantrell T, Langridge J, et al. Should we give detailed advice and information booklets to patients with back pain? A randomised controlled factorial trial of self management booklet and doctor advice to take exercise for back pain. Spine 2001;26:2065-72.

18 Burton AK, Waddell G, Tillotson KM, Summerton N, Information and advice to patients with back pain can have a positive effect: a randomised controlled trial of a novel educational booklet in primary care. Spine 1999;24:2484-91

19 Peterson T, Kryger P, Ekdahl C, Olsen S, Jacobsen S. The effect of McKenzie therapy as compared with that of intensive strengthening training for the treatment of patient with sub-acute or chronic low back pain. Spine 2002;27:1702-9.

20 Prescott RJ, Counsell CE, Gillespie WJ, Grant AM, Russell IT, Kiauka S, et al. Factor that limit the quantity number and progress of randomised controlled trials Health Technol Assess 1999:3:7
21 Ong C-K, Doll H, Bodeker G, Stewart-Brown S. Use of osteopathy or chiropractic services among people with back pain: a UK population survey. Health Soc Care Community 2004;12:265-73.

22 Klaber Moffett J, Torgerson D, Bell-Syer S, Lackson D, Llewlyn-Phllips H, Farrin A, et al Randomised controlled trial of exercise for low back pain: clinical outcomes, costs and preferences. BMJ 1999;319:270-83.

(Accepted 19 July 2004)

doi $10.1136 /$ bmj.38216.868808.7C

Division of Health in the Community, Warwick Medical School, University of Warwick, Warwick CV4 7AL

Helen Frost research fellow

Sarah E Lamb professor of rehabilitation

Sarah Stewart-Brown professor of public health

Health Services Research Unit, Department of Public Health, University of Oxford Helen A Doll medical statistician

Nuffield Orthopaedic Centre NHS Trust, Oxford

Patricia Taffe Carver trial coordinator

Correspondence to: H Frost h.frost.1@warwick.ac.uk 